\title{
Selecting women for breast cancer chemoprevention and what agents should be used
}

\author{
J Cuzick
}

\author{
From Familial Aspects of Cancer 2011 Research and Practice: A combined meeting of kConFab, Australian \\ Breast Cancer Family Study, Australian Colorectal Cancer Family Study, Australian Ovarian Cancer Study, \\ Family Cancer Clinics of Australia and New Zealand and kConFab \\ Kingscliff, Australia. 23-26 August 2011
}

Recent evidence on the chemoprevention of breast cancer has come from a number of sources:

1) Recent data on two new SERMs - lasofoxifene and arzoxifene- suggests they might be an attractive option, but further details are needed to fully evaluate their role.

2) Update on the tamoxifen and raloxifene preventive trials have shown a continued benefit after treatment completion, and an overview is ongoing to combine all the post-treatment data on risks and benefits. Latest results from the STAR trial indicate that raloxifene is less efficacious than tamoxifen but has fewer side effects. A full new overview is in progress.

3) A report from the ATAC trial indicating that the occurrence of endocrine symptoms predicts response to both tamoxifen and anastrozole may also have relevance in the preventive setting.

4) Long term follow-up of the adjuvant trials using aromatase trials has provided new evidence on the duration of a potential preventive effect by looking at isolated new contralateral tumours. This has been an excellent model for tamoxifen and may well also be so for the AIs.

5) A very recent report from the MAP3 (Goss, NEJM,2011) indicates that after 35 months median follow up, a $60 \%$ reduction in new tumours was seen, confirming predictions made from contralateral tumours in adjuvant trials.

6) New data confirm the long term protective effect of aspirin on breast cancer, but suggests it needs to be

Centre for Cancer Prevention, Wolfson Institute of Preventive Medicine, Queen Mary University of London, Charterhouse Square, London EC1M 6BQ, UK

(c) 2012 Cuzick; licensee BioMed Central Ltd. This is an Open Access article distributed under the terms of the Creative Commons Attribution License (http://creativecommons.org/licenses/by/2.0), which permits unrestricted use, distribution, and reproduction in any medium, provided the original work is properly cited. taken for at least 5 years to get a benefit. Mixed data have appeared for the statins.

Published: 12 April 2012

\section{Reference}

1. Cuzick J, DeCensi A, Arun B, Brown PH, Castiglione M, Dunn B, Forbes JF, Glaus A, Howell A, von Minckwitz G, Vogel V, Zwierzina H: Preventive therapy for breast cancer: a consensus statement. Lancet Oncol 2011 12:496-503,

doi:10.1186/1897-4287-10-S2-A10

Cite this article as: Cuzick: Selecting women for breast cancer chemoprevention and what agents should be used. Hereditary Cancer in Clinical Practice 2012 10(Suppl 2):A10.

Submit your next manuscript to BioMed Central and take full advantage of:

- Convenient online submission

- Thorough peer review

- No space constraints or color figure charges

- Immediate publication on acceptance

- Inclusion in PubMed, CAS, Scopus and Google Scholar

- Research which is freely available for redistribution

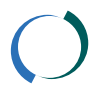

